\title{
Laura Tucker y Lois Sherwood (2020). Entender el cambio climático. Información y recursos para el profesorado. Madrid: Narcea. 155 págs. ISBN: 978-84-277-2752-6. ePdf: 978-84-277-2753-3. ePub: 978-84-277-2754-0
}

\author{
Alberto José Pazo Labrador ${ }^{1}$ \\ ${ }^{1}$ Universidad de Vigo.apazo@uvigo.es
}

Recibido: $19 / 1 / 2021$

Aceptado: 26/3/2021

Copyright $(C)$

Facultad de CC. de la Educación y Deporte.

Universidad de Vigo

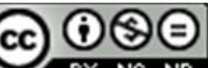

Dirección de contacto: Alberto José Pazo Labrador

Facultade de Ciencias da Educación e do Deporte

Campus A Xunqueira, s/n

36005 Pontevedra
El libro Entender el cambio climático. Información y recursos para el profesorado, está escrito por dos profesoras de Ciencias, Laura Tucker y Lois Sherwood, preocupadas por la educación y la concienciación ambiental $y$, especialmente, por el clima global, sus alteraciones y su devenir. Dos profesoras que además son activistas en el sentido más positivo del término -basta leer su currículum-, que aplican sus conocimientos y experiencias a educar, divulgar y concienciar sobre un problema evidente, presente en nuestras vidas cotidianas con sus consecuencias cada vez más tangibles y menos teóricas, como es el cambio climático y la subsiguiente transformación de las condiciones ambientales y de muchas de las pautas más asentadas de su distribución geográfica tal y como las conocemos. Los procesos globales se hacen más patentes que nunca en la actualidad, y cada vez hay más evidencias científicas de que una de las consecuencias del cambio climático - una más entre todas las posibles- es la expansión de pandemias como la que está azotando a la Humanidad desde hace más de un año. Aunque las preocupaciones de las sociedades puedan haberse desviado hacia estas circunstancias que afectan directamente a nuestra salud y a nuestro día a día, la concienciación sobre el cambio climático y los problemas ambientales debe estar en la cima del orden de prioridades, porque en este mundo globalizado observamos cómo las interacciones entre fenómenos físicos y actuaciones humanas nos conducen por derroteros insospechados que deben llevarnos a actuar ya, como colectivos y como individuos, de forma decidida. De eso trata este libro-guía que es mucho más que un libro-guía, porque traspasa los límites de una mera propuesta didáctica y de fomento de las vocaciones STEM para abordar decididamente el cambio de mentalidades y modos de actuación en los discentes y en la sociedad en la que se integran, mediante el desarrollo del pensamiento crítico y del aprender haciendo.

Porque la propuesta asume formalmente el modelo constructivista de aprendizaje, orientado a problemas relevantes, mediante el cual el alumnado de Primaria o de Secundaria va creando su conocimiento con experiencias y actividades que lo implican en la identificación, valoración y realización de propuestas relacionadas con el cambio climático. El discente se convierte, así, en un sujeto activo en su aprendizaje pero también en un activista en su vida cotidiana porque atesorará pruebas que sustentarán un conocimiento que motive a la acción para la solución de problemas. Para ello se le proporcionará el "andamiaje" que le permita llevar a cabo sus propias investigaciones y obtener sus conclusiones fundamentadas sobre el cambio climático. En esta línea, no podemos estar más de acuerdo con la concepción 
científica de las autoras: la Ciencia no es solamente someterse a métodos de trabajo formales y rígidos, en un proceso lineal de formulación de hipótesis, diseño de experimentos, recogida de datos y elaboración de conclusiones; la ciencia debe basarse también, y sobre todo, "en la creatividad y en pensar con originalidad. Es un proceso iterativo donde las conclusiones alimentan nuevas preguntas y las pruebas que se van consiguiendo se utilizan para diseñar nuevas soluciones" (p. 137); planteamiento acorde con las prácticas científicas y técnicas de los NGSS (Next Generation Science Standars) que impregnan toda la propuesta.

El trabajo se articula con un capítulo introductorio y nueve apartados que se corresponden cada uno a las nueve sesiones con las que se propone desarrollar la Unidad Didáctica, dejando margen sin embargo a la iniciativa de cada docente para organizar y adaptar el contenido a sus necesidades, intereses y nivel educativo de inserción. El capítulo introductorio se titula Indicaciones al profesorado para impartir cada tema sobre el cambio climático y es en el que se ponen de manifiesto y clarifican los objetivos, procedimientos y plan de trabajo para el desarrollo de los contenidos. Además de asumir formalmente el modelo constructivista para el aprendizaje y la importancia de aprender haciendo para consolidar una mentalidad científica en los alumnos y alumnas, se diseña la estructura común de los capítulos, y lo que llaman el background necesario para los estudiantes y sobre todo para los profesores: es decir, el contenido de fondo que es preciso tener para poder trabajar adecuadamente los temas. Para ello se aclaran nociones como la de carbono natural y carbono retenido, se hace una muy buena síntesis histórica de los estudios sobre el efecto invernadero y el cambio climático, y se realiza la aclaración, necesaria, de las diferencias entre los términos calentamiento global y cambio climático: el primero hace alusión al calentamiento de la atmósfera, las tierras y los océanos, generalmente por causas humanas como la quema de combustibles fósiles que libera el carbono retenido, la emisión de aerosoles que reflejan la luz solar o la destrucción e incendio indiscriminado de superficies forestales; mientras "cambio climático" se refiere tanto al calentamiento como a los efectos del calentamiento, perceptibles y padecidos por el ser humano, y que el alumnado puede experimentar directa o indirectamente en su vida cotidiana: mayor frecuencia y virulencia de los episodios de tormentas, sequías más intensas y prolongadas en algunos lugares (aunque aquí se podría hablar -y no está en nuestro ánimo cuestionar nada ya que estamos de acuerdo completamente con los postulados del libro-, de cierta fragilidad en la memoria de las personas, al menos en nuestro país, sobre algunos eventos climáticos extremos que acontecían hace algunas décadas, incluso hace pocos años, aparte de que en el "riesgo" de sequía tiene mucho que ver la actuación del ser humano), el retroceso de las masas glaciares... Es evidente que, a medida que el planeta se calienta, entra en juego una mayor cantidad de energía calórica para hacer funcionar los elementos del medio físico como los vientos, el ciclo del agua o la corriente en chorro en altura, y aunque este cambio puede ser por motivos naturales (hay pruebas retrospectivas de ello) las causas más evidentes están en la actuación humana desde el inicio de la Revolución Industrial y la quema masiva de combustibles fósiles con la consiguiente liberación del carbono retenido. Y la constatación incuestionable de estas causas debe mover a la reflexión y a la comprensión de que no hay que creer o no creer en el cambio climático, sino que, si se adopta un punto de vista y un proceder científico, las 
pruebas y los hechos a nuestro alcance sobre el mismo se demuestran incontestables. "No "creemos" en el cambio climático; "aceptamos" los resultados de decenas de miles de estudios y documentos de científicos de renombre que muestran que nuestra Tierra se está calentando, lo que resulta en un cambio de clima" (p. 22)

No ha lugar, como dicen las autoras, a plantear controversias o debates cuando el 97\% de los científicos que se han dedicado a ello están de acuerdo en constatar la validez tanto de las causas como de las consecuencias. El negacionismo, por lo tanto, es un mero ejercicio voluntarista que se da de bruces con hechos irrefutables. O más bien, la controversia deriva de una cuestión económica, o política, antes que científica. De ahí lo que se decía más arriba acerca de configurar una mentalidad crítica con base científica en el alumnado.

La utilización de una metodología constructivista, mediante la cual el discente de Primaria o de Secundaria va "haciendo" su conocimiento con experiencias y actividades que lo implican en el registro, identificación y valoración de hechos, y en la realización de propuestas sobre el cambio climático, convierte al alumnado como decíamos no solo en sujeto activo en su aprendizaje sino también en un activista en la vida real: algo muy necesario como se está demostrando, pues las soluciones a los problemas vendrán, sin duda, de los cambios actitudinales y comportamentales de los ciudadanos.

La estructura de los nueve temas-sesiones es similar, aportando procedimientos, recursos, background para profesores, ideas para reflexionar y material interesante como son las entrevistas a "agentes en la lucha contra el cambio climático", es decir, aquellas personas, entidades o instituciones que tienen un comportamiento activo para intentar atajar o mitigar las consecuencias del problema, como un espejo en el que mirarse para diseñar una emulación eficaz. Los temas son transversales, en el ámbito de las Ciencias, pero implicando a un espectro disciplinar más amplio. En nuestra opinión, y teniendo en cuenta el "corsé curricular", el cronograma propuesto peca de amplio y ambicioso - lo cual no es algo negativo, ni mucho menos-, solo realizable en el marco de un proyecto de aprendizaje transversal. En cualquier caso, el material y los recursos aportados a los docentes de cualquier nivel -muy adecuado por ejemplo para la formación de maestros dada su amplitud y actualidad- es algo que hace al libro muy valioso. El procedimiento de acceso a la información, selección, organización, lectura crítica, planteamiento de preguntas y búsqueda de soluciones, trabajo en grupos, respuesta activa ante desafíos, implicación con agentes sociales, visibilización de los resultados de las investigaciones en el entorno social... contribuye con creces a crear esa mentalidad de alumno-miembro de la sociedad concienciado, activista, capaz de investigar por sí mismo y de planificar acciones positivas, capaz de enfrentar y mitigar las consecuencias de un problema relevante que afecta a su vida cotidiana.

En suma, el libro está impregnado de la concepción necesaria de la educación como aquel proceso que contribuye a crear ciudadanos y ciudadanas responsables concienciados y concienciadas ante los desafíos de un mundo en el que más temprano que tarde serán los protagonistas de su supervivencia. Y por ello, porque es algo en lo que todos nos jugamos mucho, los educadores y educadoras de todos los niveles, deberían conocerlo y leerlo para convertirse también en "activistas" responsables. 